\title{
2017 DILA International Conference and 2017 DILA Academy \& Workshop
}

The 2017 DILA International Conference entitled "International Law and the Legacy of Colonialism and Imperialism: Revisited" and the 2017 DILA Academy and Workshop on "Chinese Contributions to the Development of International Law" and "State Practice in International Law in Asian States in the Year 2016 " was held on June 22 to June 24 at KoGuan Law School on the campus of Shanghai Jiao Tong University in Shanghai, China.

The conference opened in the morning of June 23 with a welcome address by Guifang Julia Xue, Director of the Center for Rule of Ocean Law Studies and Center for Polar and Deep Ocean Development and Chair Professor of KoGuan Law School, Shanghai Jiao Tong University, China and Seokwoo Lee, Chairman for the Development of International Law in Asia (DILA) and Professor of International Law at Inha University Law School, Korea.

Session one of the conference was entitled "The Past: The Vestiges of Colonialism" and was chaired by Guifang Julia Xue. The first presenter, Hee Eun Lee, Handong International Law School, Korea, presented his paper "Colonialism and International Law: Legal Positivism as a Theoretical Foundation". The second presenter, Si Jin Oh, College of Liberal Arts, Sahmyook University, Korea, presented on "The Relevance of Colonial International Law Today". The final presenter of the session was Sung-Won Kim, Wonkwang University School of Law, Korea who presented his paper "A Revisit to the Eastphalia: woher, warum und wohin".

Session two, "The Contribution of Minority Perspectives to the Development of International Law - Part 1" was chaired by Hee Eun Lee. The first presenter, Pyoung Keun Kang of Korea University School of Law examined "The Historical Legacies in Korea-Japan relations and the Korean Courts with Specific References to the Issues of 'Enforced Sexual-Slaves'. The second presenter, Seung-Jin Oh, College of Law, Dankook University, Korea presented on his paper, "The 'Final and Irreversible' 2015 South Korea-Japan Comfort Women Deal: Revisited". The final presenter of the session, Lan Hua of the China University of Political Science and Law presented on "Indigenous People and Right of Cultural Property in International Law".

Session three, "The Present: The Contribution of Minority Perspectives to the Development of International Law - Part 2" and was chaired by Seokwoo Lee. The first presenter was Xu Bujun of the University of Hong Kong Law Faculty who presented on "The First Sino-Japanese War and the Inter-temporal 
Rule". The second presenter was Zhang Xinjun, Tsinghua University Law School, China who examined "Reparation for the Chinese Victims of Gross Violations of Rules of Jus In Bello arising out of Sino-Japanese War". Lastly, Zhang Xiaoshi of the University of Hong Kong Law Faculty presented on "Rethinking Narrative on Nineteenth Century International Law: Is There a Chinese Intellectual Connection?"

The final session of the day entitled "The Future Constructive Contribution of Colonialism" was chaired by Dustin Kuan-Hsiung Wang of National Taiwan Normal University. The first presentation was given by Deok-Young Park of Yonsei Law School, Korea who discussed the "Paris Agreement and its Subsequent Negotiations: Conflict of Interests between States". Following, John Anthony (Tony) Carty, Tsinghua University Law School, China gave his talk on "International Law and China: Heads (Coin Toss) the West Wins, Tails China Loses". The conference then came to a close with final remarks by chairpersons Guifang Julia Xue and Seokwoo Lee.

The following day, June 24, the 2017 DILA Academy and Workshop was opened with a welcome address by Guifang Julia Xue and Seokwoo Lee. Session one, titled "Chinese Contributions to the Development of International Law - Part 1" was chaired by Seokwoo Lee. The first speaker of the session was He Zhipeng of Jilin University School of Law, China who presented on "Challenges and Possibilities for China to Contribute to the International Legal System". The presentation was followed by Liao Li of Wuhan University who spoke on "China and International Disputes". The final speaker of the session was Zho Jiang of the Research Center of the Law and Policy of the Sea and Space and Southwest University of Political Science and Law, China who presented on "The Metaphysical Interpretation on the New Maritime Silk Road Strategy".

Session two was titled "Chinese Contributions to the Development of International Law - Part 2" and was chaired by Seokwoo Lee. The first presenter was Matthias Vanhullebusch of KoGuan Law School, Shanghai Jiao Tong University, China who spoke on "China's Air Defence Identification Zone: Towards a Crystallization of a New International Custom". This was followed by Zhao Jun of Zhejiang University Law School, China who presented on "Opportunities and Challenges: Mutual Encouragement and Interactions between International Rule of Law and China's Rule of Law". Lastly, Xie Jingjing of the University of International Relations, China presented on "An Overview of the Enforcement of International Law in the People's Republic of China: Transformation, Adoption and Development".

Session three was titled "State Practice in International Law in Asian States in the Year of 2016 - Part 1" and was chaired by Seokwoo Lee. First, Guifang 
Julia Xue spoke on "State Practice in International Law in China in the Year of 2016". Afterwards, Kanami Ishibashi of Tokyo University of Foreign Studies, Japan presented on "State Practice in International Law in Japan in the Year of 2016". Finally, Dustin Kuan-Hsiung Wang, National Taiwan Normal University, discussed the "State Practice in International Law in Taiwan in the Year of $2016 "$.

Session four was titled "State Practice in International Law in Asian States in the Year of 2016 - Part 2" and chaired by Seokwoo Lee. Buhm-Suk Baek of the College of International Studies, Kyung Hee University, Korea discussed "State Practice in International Law in Korea in the Year of 2016". He was followed by Eon Kyung Park and Tea-Gil Kim of Kyung Hee University Law School, Korea who spoke on "Regulations and Measures relating to Living Modified Organisms in Korea". Lowell Bautista of the University of Wollongong School of Law, Australia followed with a discussion of "State Practice in International Law in the Philippines in the Year of 2016". Lastly, Tran Viet Dung of Ho Chi Minh City University of Law, Vietnam presented on "State Practice in International Law in Vietnam in the Year of 2016".

Session five was a special session on "Climate Change and International Law" chaired by Seokwoo Lee. The first presentation was given by Seungmin Kim of Yonsei University, Korea who spoke on "Climate Change as Threat to Security? Same Bed, Different Dreams". Next, Il Ho Lee of Yonsei University presented on "Technology Transfer as a Response to Climate Change: Half Full or Half Empty?"

Guifang Julia Xue and Seokwoo Lee then offered their final remarks and closed the 2017 DILA Academy and Workshop.

Seokwoo Lee
Co-Editor-in-Chief

Hee Eun Lee

Co-Editor-in-Chief 